Original article

\title{
Inverted U shaped effect of nicotine on the severity of depressive symptoms: A population-based survey
}

\author{
Ammar W. Ashor* \\ Department of Pharmacology, College of Medicine, University of Al-Mustansiriyah, Baghdad 14132, Iraq
}

\section{A R T I C L E I N F O}

\section{Article history:}

Received 31 March 2013

Accepted 15 June 2013

Available online 8 July 2013

\section{Keywords:}

Beck Depression Inventory

Nicotine dependence

Medical students

Tobacco smoking

Iraq

\begin{abstract}
A B S T R A C T
Objectives: To investigate whether that nicotine concentration represented by the degree of smoking dependence variably influence the rate and severity of depressive symptoms.

Methods: Cross-sectional, analytical study, involving 300 medical students selected by random sampling techniques were asked to complete a questionnaire contains three parts: demographic information, Beck Depression Inventory with cutoff point for depression is 17 and the Fagerström Test for Nicotine dependence with cutoff point for severe dependence is five.

Results: A total of 233 medical students completed the questionnaire; their mean age was (21.38 \pm 1.74$)$. The rate of smoking was $22.7 \%$ while that of depression was $32.2 \%$. Low dependent smokers in contrast to other groups of smokers and non-smokers display the lowest rate of depressive symptoms (15\%), while the highest rate recorded among severely dependent smokers (71.4\%, $p=0.0001)$. After adjustment of other risk factors, regression analysis reveal that severe dependent smokers associated with 12.5 odds of depressive symptoms than non-smokers ( $p=0.0001$, C.I. $4.10-38.29)$.

Conclusion: In comparison with light and moderate smokers, heavy smokers demonstrate higher risk of depressive symptoms in medical students.

Copyright (c) 2013, InPharm Association, Published by Reed Elsevier India Pvt. Ltd. All rights reserved.
\end{abstract}

\section{Introduction}

Many epidemiological studies have shown a strong association of smoking with depression, 1,2 it has been found that about $50 \%$ of the individuals suffering from depression reported to be smokers, on the other hand, regular smokers display more depressive symptoms, more frequent and severe episodes of depression and higher rate of suicidal ideation. ${ }^{3}$

The common explanation of this association is the selfmedication hypothesis, which state that depressed patients smoke to relieve their symptoms. ${ }^{4}$ This hypothesis was constructed on the reports of smokers who experience an improved sense of well-being, greater calm, better attention, and superior ability to concentrate after smoking. ${ }^{5}$ Additionally, nicotine increases the secretion of dopamine in the limbic system which may also contribute to the euphoria and addictive potential of nicotine. ${ }^{6}$

However, recently the self-medication hypothesis undergoes significant criticism because of the many published prospective studies which prove that smoking increase the risk of depression and not the reverse. ${ }^{7,8}$ These studies explain the previous reported

\footnotetext{
* Tel.: +964 7901261613 (mobile).

E-mail address: ammar_w_78@yahoo.com.
}

improvement among smokers as following: smoking only generates mood changes in nicotine-deprived smokers, but these only represents the restoration of normal moods, and it's found that when non-deprived smokers had a cigarette, their mood ratings remain unaltered. ${ }^{9}$

Many factors implicated in the variability of nicotine effects in the brain like nicotine dose, duration and frequency of administration. ${ }^{10-12}$ In the present study, we propose that there is diverse influence of nicotine on mood according to the level of dependence; it means that low nicotine exposure may produce positive effects while high dose of nicotine (severe nicotine dependence) associated with negative emotional effect and depressive symptoms.

The aim of the present study is to investigate whether nicotine concentration represented by the degree of smoking dependence has variable influence on the rate and severity of depressive symptoms among medical students.

\section{Methods}

Study design: a cross-sectional analytical study, conducted on medical students in the college of medicine, University of AlMustansiriya, Baghdad, Iraq from October to December 2011. The study follows the Helsinki Declaration regarding humans involved 
in clinical trials and was approved by the local scientific and ethical committee in the medical college.

Participants: students were voluntarily invited to participate during their attendance in the laboratory, sessions, or lectures. First, students informed about the anonymity of the questionnaire and that the information is confidential, then verbal consent were taken from those who were willing to participate.

Measures: the questionnaire composed of three parts:

- General demographic questions: this part contains general information about students (age, sex, stage of study).

- Beck Depression Inventory-II: this questionnaire composed of 21 items, assessing many symptoms that occur in depressive patients like (sadness, pessimism, guilt, fatigue, anorexia, crying, suicidal thoughts, etc.); these symptoms were phrased in four alternative descriptions (four statements). Every set of statements was written in the order of increasing distress. The participants had to select, for each item, the response alternative that correspond best to their situation for now and the past week. The total score was obtained by adding the values of all items, each ranged from 0 to 3 , with the total score ranged from 0 to $63,{ }^{13}$ and a cut score of either 17 or 18 provide the best balance between sensitivity and specificity. ${ }^{14}$

- Fagerström test for nicotine dependence (FTND): those who were reported to be smokers then fill the FTND questionnaire in addition to questioning their age of starting to smoke. Recent systemic review of the FTND questionnaire found that the reliability of this scale ranged from 0.65 to 0.91 with sensitivity (0.75) and specificity of $(0.80)$ and the Cronbach's alpha of internal consistency ranged 0.55 to $0.74 .{ }^{15}$ The FTND scale composed of six items questions (time taken for the first cigarette after waking up, ability to refrain from smoking in forbidden places, how many cigarettes smoked per day, etc.). The total score for the FTND ranged between 0 and 10; a score ranged from 0 to 3 regarded as mild dependence, while score of 4-5 as moderate dependence and scoring higher than 5 considered as severe smoking dependence.

\subsection{Statistical analysis}

Analyses of the results were done by using PASW Statistics 18 software (SPSS Inc., Chicago, IL). The numerical variables expressed as mean $\pm S D$ and analyzed by using independent sample $t$-test for the comparison of two independent groups or the Analysis of Variance test (ANOVA) for the comparison of more than two groups (Tukey test for post hoc analysis). Categorical variables expressed as number (\%) and analyzed with Pearson's chi-squared test for univariable analysis, and multivariable analysis done to find the association between groups in adjustment for sex, age, and stage of the students using logistic regression analysis, Odd ratio and its class interval were reported; in all the above tests a $p$ value less than 0.05 were considered as statistically significant.

\section{Results}

Two hundred and thirty three medical students participated in the study; their age ranged from 18 to 26 with a mean of $(21.38 \pm 1.74)$, female represents $(43.6 \%)$ of all the students. Smoking prevalence was (22.7\%), their age of onset of smoking ranged from 14 to 23 years. The range of the students score on Beck Depression Inventory ranged between 2 and 41, and (32.2\%) of all medical students demonstrate depressive symptoms. The distribution of the participants regarding years of study and their smoking status with other parameters presented in Table 1 below.
Table 1

Participants demographic characteristics.

\begin{tabular}{|c|c|}
\hline $\begin{array}{l}\text { Demographic characteristics } \\
(\text { mean } \pm \text { SD) }\end{array}$ & $\begin{array}{l}\text { Number }(\%) \text { [total number of } \\
\text { participants = 233] }\end{array}$ \\
\hline \multicolumn{2}{|l|}{ Age $(21.38 \pm 1.74)$} \\
\hline \multicolumn{2}{|l|}{ Gender } \\
\hline - Male & $131(56.2)$ \\
\hline - Female & $102(43.6)$ \\
\hline \multicolumn{2}{|l|}{ Stage } \\
\hline - First & $34(14.6)$ \\
\hline - Second & $44(18.9)$ \\
\hline - Third & $44(18.9)$ \\
\hline - Fourth & $36(15.5)$ \\
\hline - Fifth & $39(16.7)$ \\
\hline - Sixth & $36(15.5)$ \\
\hline Non-smokers & $180(77.3)$ \\
\hline Smokers & $53(22.7)$ \\
\hline - Low dependence & $20(8.6)$ \\
\hline - Moderate dependence & $12(5.2)$ \\
\hline - Severe dependence & $21(9.0)$ \\
\hline \multicolumn{2}{|c|}{ Age of start smoking $(17.36 \pm 2.43)$} \\
\hline \multicolumn{2}{|c|}{ Beck Depression Inventory $(13.63 \pm 7.93)$} \\
\hline - $\quad<17$ & $158(67.8)$ \\
\hline - $\quad \geq 17$ & $75(32.2)$ \\
\hline
\end{tabular}

Depressed students significantly older, start smoking at earlier age, having higher FTND score than non-depressed (see Table 2). Female students demonstrate significantly higher rate of depression than male students ( $42.2 \%$ vs. $24.4 \%$ for females and males respectively, $p=0.004$ )

Table 3 demonstrate that severe dependent smokers start smoking at earlier age $(p=0.001)$ and have higher mean depression score $(p=0.001)$ than other groups. Low dependent smokers (Fig. 1) in contrast to other groups of smokers and non-smokers demonstrate the lower rate (15\%) of depressive symptoms $(p=0.0001)$, while the highest rate seen among severely dependent smokers (71.4\%).

In Table 4, univariate logistic regression analysis done using depression as dependent variable, demonstrate that age, sex, age of onset of smoking and the FTND score significantly associated with depression. Female students display 2.25 times higher odds of depressive symptoms than their male peer students. In the same table mentioned before, severe smoking dependence has 6.15 times higher odds of depressive symptoms than non-smokers.

Multivariate logistic regression analysis using depression as dependent variable with age, age of smoking and sex as covariate, demonstrate that severe smoking dependence significantly associated with depression with odds of 12.33 ( $p=0.007$, C.I: $1.98-$ 76.61 ) in comparison with non-smokers.

\section{Discussion}

Nicotine follow typically an 'inverted U' effects on cognition and behavior, i.e. nicotine self-administration (positive re-enforcing

Table 2

Comparison between non-depressed and depressed students regarding their age, Beck Depression Inventory (BDI), age of start smoking and their Fagerström test for nicotine dependence (FTND).

\begin{tabular}{lclll}
\hline & $\begin{array}{l}\text { Non-depressed } \\
(n=158) \\
\text { mean } \pm \text { SD }\end{array}$ & $\begin{array}{l}\text { Depressed } \\
(n=75) \\
\text { mean } \pm \text { SD }\end{array}$ & $P$ value & Class interval \\
\hline Age & $21.21 \pm 1.73$ & $21.75 \pm 1.72$ & $0.027^{*}$ & $0.061-1.015$ \\
BDI & $9.03 \pm 3.82$ & $23.33 \pm 5.07$ & $0.038^{*}$ & $13.12-15.62$ \\
Age of smoking & $18.00 \pm 2.30$ & $16.52 \pm 2.37$ & $0.026^{*}$ & $0.180-2.777$ \\
FTND score & $3.50 \pm 2.68$ & $6.26 \pm 2.76$ & $0.001^{*}$ & $1.246-4.276$ \\
\hline
\end{tabular}

*Significant difference between groups using independent sample $t$-test. 
Table 3

Comparison between students smoking status, FTND, and BDI.

\begin{tabular}{llllc}
\hline & $\begin{array}{l}\text { Non-smokers } \\
(N=180)\end{array}$ & $\begin{array}{l}\text { Low } \\
\text { dependence } \\
(N=20)\end{array}$ & $\begin{array}{l}\text { Moderate } \\
\text { dependence } \\
(N=12)\end{array}$ & $\begin{array}{l}\text { Severe } \\
\text { dependence } \\
(N=21)\end{array}$ \\
\hline Age & $21.3 \pm 1.7$ & $21.6 \pm 2.2$ & $21.5 \pm 1.4$ & $22.2 \pm 1.2$ \\
Age of smoking & & $18.5 \pm 2.7$ & $18.1 \pm 1.9$ & $15.9 \pm 1.6^{*}$ \\
FTND score & & $1.5 \pm 1.1$ & $4.5 \pm 0.5$ & $7.9 \pm 1.4^{*}$ \\
BDI & $12.9 \pm 7.7$ & $12.2 \pm 6.5$ & $16.0 \pm 7.4$ & $19.9 \pm 8.7^{*}$ \\
\hline
\end{tabular}

FTND: Fagerström Test For Nicotine Dependence; BDI: Beck Depression Inventory. All values are mean $\pm \mathrm{SD},{ }^{*} P<0.001$ compare to low and moderate dependence (One-way ANOVA followed by Tukey's post hoc test).

effect) require optimum doses near the top of the inverted $U$, but if the dose was too high, aversive effects dominated. ${ }^{10,16}$

In the present study, low dependent smokers (low nicotine) display lower odds of depressive symptoms than non-smokers and other categories of smokers, while severely dependent smokers (high nicotine intake) associated with high risk of depressive symptoms than the other groups after adjustment of other risk factors.

Animal studies demonstrated that nicotine had antidepressant effects comparable to currently used antidepressant agents. ${ }^{17} \mathrm{Be}-$ sides, intravenous administration of nicotine have been shown to creates a sense of euphoria that is hard to distinguish from the effects of other drugs of abuse such as cocaine and alcohol, ${ }^{5}$ furthermore, cigarette smoke contains substances that have Monoamine oxidase enzyme inhibition which adds to the antidepressant effect as well. ${ }^{18}$

However, Bolam et al, in their study, claimed that there is evidence of dose-response relationship between number of cigarettes smoked per day and depression (OR $=1.46$, C.I. 1.13-1.89) ${ }^{19}$ Furthermore, Boden et al proved that increasing level of nicotine dependence were significantly associated with increasing in the rates of depressive symptoms. ${ }^{7}$

Moreover, Kang and Lee in their longitudinal study demonstrated that smoking less than ten cigarette per day associated with 1.5 odds of depressive symptoms while smoking more than 40 cigarette per day had 7.3 odds of depression in comparison with non-smokers. ${ }^{20}$

Light smokers reported lower perceived stress, fewer symptoms of depression and greater positive affect in comparison with heavy smokers. ${ }^{21}$ Heavy smokers reported higher rate of stress than nonand light smokers, ${ }^{22}$ and it is found that suicide behavior was more frequent among heavy smokers than among light smokers. ${ }^{23}$

Several factors collaborate to the depressant effect of high nicotine concentration represented by severe smoking dependence. First, nicotine injected to animals with low circulating levels of nicotine results in stimulation of nicotinic receptors and release of dopamine, while injecting nicotine to animals with blood nicotine concentration similar to those found in the plasma of habitual

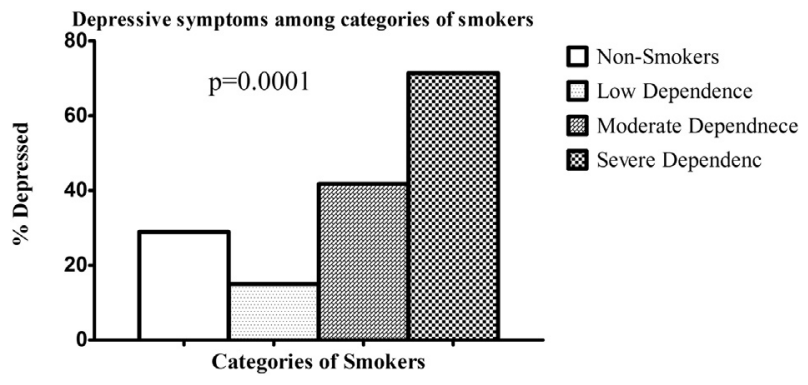

Fig. 1. The rate of depression among the different categories of smokers.
Table 4

Univariable association of the Demographic participants' characteristics.

\begin{tabular}{lrllc}
\hline & Wald & $P$ value & Odds ratio & Class interval \\
\hline Age & 4.774 & $0.029^{*}$ & 1.20 & $1.02-1.42$ \\
Sex & 8.105 & $0.004^{*}$ & 2.25 & $1.28-3.94$ \\
Stage & 0.653 & 0.419 & 1.07 & $0.91-1.26$ \\
Age of smoking & 4.554 & $0.033^{*}$ & 0.752 & $0.58-0.98$ \\
FTND score & 9.419 & $0.002^{*}$ & 1.427 & $1.14-1.79$ \\
Non-smokers & 15.710 & & & \\
Low dependence & 1.659 & 0.198 & 0.434 & $0.122-1.55$ \\
Moderate dependence & 0.861 & 0.353 & 1.758 & $0.534-5.79$ \\
Severe dependence & 12.681 & $0.0001^{*}$ & 6.154 & $2.26-16.73$ \\
\hline
\end{tabular}

FTND: Fagerström Test for Nicotine Dependence; BDI: Beck Depression Inventory cutoff value ( $\geq 17$ ) among medical students.

${ }^{*} P<0.05$ for the logistic regression analysis comparing depressed with nondepressed students for the above variables.

smokers for much of the day fails to stimulate many of dopamine neurons in the reward center. ${ }^{12}$

Second, continuous administration of nicotine associated with reduction in the serotonin and GABA transmitters, these transmitters important in the regulation of mood. 6,24

Third, heavy smokers have higher concentration of stress hormones (CRF, ACTH, corticosterone) than light and non-smokers, these hormones implicated in the causation of depression. ${ }^{22}$

Fourth, the cholinergic hypothesis of depression, this state that high acetylcholine may be responsible for the onset of depression. The supporting evidence of this theory includes the following: elevated choline level in the brain of depressed patients, physostigmine (acetylcholine agonist) exacerbate depressed mood while scopolamine (acetylcholine antagonist) found to be effective antidepressant. $^{23}$

The present study comprises many limitations. First, it is crosssectional study, therefore causal association between the degree of tobacco dependence and depressive symptoms difficult to be elucidated. Second, self-reported measurement of nicotine dependence and depression enclose many problems like subjectivity and bias in reporting. Third, small sample size which is not representative to the whole population (single college), therefore this put limits on generalization of the results.

Prospective studies are vital to further elucidate the relationship between the degree of smoking dependence and depression, these studies required to be more objective by measuring serum cotinine level as well as implementing diagnostic interview as a mean for diagnosis and follow up of depressed patients.

\section{Conclusions}

Despite the above limitations, the present study may partially explain the controversy regarding the relationship between smoking and depression by adopting the $U$ shaped behavior of nicotine in the brain. This is done through the finding that severe dependent smokers associated with very high risk of depression in comparison with other groups.

\section{Conflicts of interest}

The author has none to declare.

\section{Acknowledgment}

Deep thanks and gratitude to Dr. Ali K. Chelab and Ahmad Natiq (4th year Medical Student) for their help in the distribution and collection of the questionnaire. 


\section{References}

1. Farrell M, Howes S, Bebbington P, et al. Nicotine, alcohol and drug dependence, and psychiatric comorbidity - results of a national household survey. Int Rev Psychiatry. 2003;15:50-56.

2. Grant BF, Hasin DS, Chou SP, Stinson FS, Dawson DA. Nicotine dependence and psychiatric disorders in the United States: results from the national epidemiologic survey on alcohol and related conditions. Arch Gen Psychiatry. 2004;61: 1107-1115.

3. Kalman D, Morissette SB, George TP. Co-morbidity of smoking in patients with psychiatric and substance use disorders. Am J Addict. 2005;14:106-123.

4. Leonard S, Adler LE, Benhammou K, et al. Smoking and mental illness. Phar macol Biochem Behav. 2001;70:561-570.

5. Quattrocki E, Baird A, Yurgelun-Todd D. Biological aspects of the link between smoking and depression. Harv Rev Psychiatry. 2000;8:99-110.

6. Aubin HJ, Rollema H, Svensson TH, Winterer G. Smoking, quitting, and psychiatric disease: a review. Neurosci Biobehav Rev. 2012;36:271-284.

7. Boden JM, Fergusson DM, Horwood LJ. Cigarette smoking and depression: tests of causal linkages using a longitudinal birth cohort. Br J Psychiatry. 2010;196: 440-446.

8. Dierker LC, Avenevoli S, Stolar M, Merikangas KR. Smoking and depression: an examination of mechanisms of comorbidity. Am J Psychiatry. 2002;159: 947-953.

9. Parrott AC. Nicotine psychobiology: how chronic-dose prospective studies can illuminate some of the theoretical issues from acute-dose research. Psychopharmacology (Berl). 2006;184:567-576.

10. Picciotto MR. Nicotine as a modulator of behavior: beyond the inverted $U$ Trends Pharmacol Sci. 2003;24:493-499.

11. Benowitz NL. Nicotine addiction. N Engl J Med. 2010;362:2295-2303.

12. Balfour DJ. The psychobiology of nicotine dependence. Eur Respir Rev. 2008;17: $172-181$.
13. Cusin C, Yang H, Yeung A, Fava M. Rating Scales for Depression. In: Baer L, Blais MA, eds. Handbook of Clinical Rating Scales and Assessment in Psychiatry and Mental Health. New York: Humana Press; 2010:8-p24.

14. Nuevo R, Lehtinen V, Reyna-Liberato PM, Ayuso-Mateos JL. Usefulness of the Beck Depression Inventory as a screening method for depression among the general population of Finland. Scand J Public Health. 2009;37:28-34.

15. Meneses-Gaya IC, Zuardi AW, Loureiro SR, Crippa JA. Psychometric properties of the Fagerström test for nicotine dependence. J Bras Pneumol. 2009;35:73-82.

16. Heishman SJ, Kleykamp BA. Singleton EG. Meta-analysis of the acute effects of nicotine and smoking on human performance. Psychopharmacology (Berl). 2010;210:453-469.

17. Andreasen JT, Henningsen $K$, Bate S, Christiansen S, Wiborg O. Nicotine reverses anhedonic-like response and cognitive impairment in the rat chronic mild stress model of depression: comparison with sertraline. J Psychopharmacol. 2011;25: 1134-1141.

18. Bacher I, Houle S, Xu X, et al. Monoamine oxidase A binding in the prefrontal and anterior cingulate cortices during acute withdrawal from heavy cigarette smoking. Arch Gen Psychiatry. 2011;68:817-826.

19. Bolam B, West R, Gunnell D. Does smoking cessation cause depression and anxiety? Findings from the ATTEMPT cohort. Nicotine Tob Res. 2011;13:209-214.

20. Kang E, Lee J. A longitudinal study on the causal association between smoking and depression. J Prev Med Public Health. 2010;43:193-204.

21. Businelle MS, Kendzor DE, Costello TJ, et al. Light versus heavy smoking among African American men and women. Addict Behav. 2009;34:197-203.

22. Richards JM, Stipelman BA, Bornovalova MA, Daughters SB, Sinha R, Lejuez CW. Biological mechanisms underlying the relationship between stress and smoking: state of the science and directions for future work. Biol Psychol. 2011;88:1-12.

23. Dome P, Lazary J, Kalapos MP, Rihmer Z. Smoking, nicotine and neuropsychiatric disorders. Neurosci Biobehav Rev. 2010;34:295-342.

24. Laviolette SR, Van der Kooy D. The neurobiology of nicotine addiction: bridging the gap from molecules to behaviour. Nat Rev Neurosci. 2004;5:55-65. 